\title{
ERCC1 Is a Predictive Biomarker for Non-small Cell Lung Cancer But Is Antibody-dependent
}

\author{
TAMIO OKIMOTO ${ }^{1}$, YUKARI TSUBATA $^{1}$, RYOSUKE TANINO $^{1}$, MIKA NAKAO $^{1}$, TAKAMASA HOTTA $^{1}$, \\ MEGUMI HAMAGUCHI ${ }^{1}$, SHUNICHI HAMAGUCHI ${ }^{1}$, ASUKA ARAKI $^{2}$ and TAKESHI ISOBE ${ }^{1}$ \\ ${ }^{1}$ Department of Internal Medicine, Division of Medical Oncology and Respiratory Medicine, \\ Shimane University Faculty of Medicine, Izumo, Japan; \\ ${ }^{2}$ Department of Organ Pathology, Shimane University Faculty of Medicine, Izumo, Japan
}

\begin{abstract}
Background/Aim: To predict the efficacy of platinum-containing chemotherapy, ERCC1 expression levels were investigated. Studies have shown changes in the performance of anti-ERCC1 antibodies; therefore, predicting chemotherapy efficacy by immunohistochemical assessment of ERCC1 is controversial. Patients and Methods: Twenty-eight patients who received platinum-containing chemotherapy and underwent computed tomography evaluation 6-9 weeks after therapy initiation were retrospectively identified. The tumor samples were evaluated in 2012 and 2018 using the latest antiERCC1 antibodies available at those times. Results: In 2012, the ERCCl H-score was significantly higher in patients with disease progression than in patients without disease progression $(p=0.019)$. Although the same trend was shown in 2018, there were some inconsistent results between the 2012 and 2018 samples. Conclusion: Patients with tumors showing low ERCC1 expression had a better disease control rate on platinumcontaining chemotherapy. However, since the performance of the antibody changed over time, standardized technology to evaluate ERCC1 expression is needed.
\end{abstract}

Lung cancer is a leading cause of cancer death worldwide. Although emerging immunotherapy changed the treatment of non-small cell lung cancer (NSCLC) patients dramatically, the response rate of the treatment is $20-40 \%$, and cytotoxic drugs are still important. After disease progression on

This article is freely accessible online.

Correspondence to: Yukari Tsubata, Department of Internal Medicine, Division of Medical Oncology and Respiratory Medicine, Shimane University Faculty of Medicine, 89-1, Enya-cho, Izumo, Shimane, 693-8501, Japan. Tel: +81 853202581, Fax: +81 853202581, e-mail: ytsubata@med.shimane-u.ac.jp

Key Words: Non-small cell lung cancer, ERCC1, platinum drug, chemotherapy. immunotherapy, a platinum-containing regimen is the standard option. Although it is a key treatment, there are side effects, and the response rate is approximately 20\% (1). Therefore, it is important to predict the efficacy of the therapy and individualize treatment plans. There are some candidate biomarkers for predicting the efficacy of a platinumcontaining regimen. Excision repair cross-complementing gene 1 (ERCC1) is one of the most investigated molecules. ERCC1 is one of several proteins that play a role in nucleotide excision repair (2); low expression of ERCC1 is thought to be associated with the efficacy of a platinumcontaining regimen (3-5). Holm et al. retrospectively identified 163 patients with inoperable NSCLC treated with carboplatin and gemcitabine and assessed their ERCC1 expression using immunohistochemistry (IHC). Patients with ERCC1-negative tumors showed longer survival compared to patients with ERCC1-positive tumors (median survival, 12.0 vs. 8.2 months; $p=0.02$ ) (6). Olaussen et al. subsequently assessed ERCC1 expression in 761 patients who were enrolled in the International Adjuvant Lung Cancer Trial (IALT) study, which compared the efficacy of adjuvant cisplatin-containing therapy with observations after complete resection of NSCLC $(7,8)$. Adjuvant chemotherapy significantly prolonged survival among patients with ERCC1negative tumors but not among patients with ERCC1-positive tumors (hazard ratio $=0.65$ vs. 1.14 , respectively). A phase III clinical trial to prospectively evaluate ERCC1 as a predictive and prognostic biomarker was not useful (9). The authors suggested that they could not replicate the previous study due to the different antibody batches used in the trials. Therefore, the usefulness of ERCC1 as a predictive biomarker is controversial, and whether the antibody batch changes the IHC results should be confirmed.

To address these issues, we retrospectively analyzed tissue samples stained and assessed for ERCC1 expression six years apart. The results show that while low ERCC1 expression was significantly associated with a better disease control ratio on platinum-containing chemotherapy, the antibody batch 
caused differences in IHC stainability. Therefore, assessment of ERCC1 expression by IHC can be a useful biomarker, but standardization is essential to its clinical use.

\section{Patients and Methods}

Study population. There were 169 retrospectively identified patients who were diagnosed with NSCLC by biopsy between 2006 and 2011 at Shimane University Hospital, Shimane, Japan. There were 152 tumor samples available for IHC staining for ERCC1. Twenty-eight patients who received platinum-containing chemotherapy and underwent computed tomography (CT) 6-9 weeks after the initiation of chemotherapy were included in this assessment of the relationship between ERCC1 expression and chemotherapy efficacy. This study was approved by the institutional review board of Shimane University (IRB approval number: 701). Written informed consent was obtained from each patient prior to participation in this study.

IHC procedures. Formalin-fixed, paraffin-embedded tumor specimens were immunostained using a BenchMark GX autostainer (Roche, Tucson, AZ, USA). Paraffin-embedded tumor material was cut into $4-\mu \mathrm{m}$-thick sections and placed onto glass slides. The slides were placed on slide heaters of BenchMark GX and deparaffinized according to the manufacturer's instructions. Antigen was retrieved by $90-$ min conditioning with a high-pH retrieval solution $\mathrm{CC} 1$ (Roche). Endogenous peroxidase activity was blocked by incubation with ultraView Universal DAB Inhibitor (Roche) for $4 \mathrm{~min}$. Slides were then incubated with a mouse monoclonal anti-ERCC1 antibody (1:200) (clone $8 \mathrm{~F} 1$; GeneTex, Irvine, CA, USA) at $37^{\circ} \mathrm{C}$ for $30 \mathrm{~min}$ and incubated with ultraView Universal HRP Multimer (Roche) for 8 min. Expression was detected using ultraView Universal DAB Chromogen, $\mathrm{H}_{2} \mathrm{O}_{2}$, and Copper (Roche) according to the manufacturer's instructions. Counterstaining was performed with Hematoxylin II (Roche), and the color was developed with Bluing Reagent (Roche) according to the manufacturer's instructions.

The presence of tumor cells and histotypes were evaluated in the Pathology Department of our Hospital. Biopsy samples were considered eligible for analysis if there were $>20$ malignant cells on the slide and the tumor morphology was preserved well. IHC staining was evaluated independently by three physicians who were blinded to the clinical data (TO, YT, and TI). Staining intensity was graded on a scale of 0 to 3 , with higher numbers indicating higher intensity. Endothelial cells in tonsil tissues were used as positive controls, with an intensity of 2. A four-category proportion score was assigned ( 0 if $0 \%, 0.1$ if $1-9 \%, 0.5$ if $10-49 \%$, and 1.0 if $\geq 50 \%$ ). This proportion score was multiplied by the staining intensity score to obtain the final semiquantitative $\mathrm{H}$-score $(8,10-12)$.

Comparison of anti-ERCC1 antibody. Tissue samples from the tumor biopsies were cut in 2012 and 2018. Slides were stained in 2012 and 2018 with the latest anti-ERCC1 8F1 antibody available at that time (lot numbers: 33499 and 821700012 , respectively). The correlation of ERCC1 expression was calculated using Pearson's product-moment correlation test.

Statistical analysis. Statistical analyses were performed using EZR software (Saitama Medical Center, Jichi Medical University, Saitama, Japan) (13). Correlations of ERCC1 expression between the 2012 and 2018 IHC results were calculated using Spearman correlation coefficients. ERCC1 expression in 2012 and 2018 was compared
Table I. Patient characteristics.

\begin{tabular}{|c|c|c|}
\hline & $\begin{array}{l}\text { All patients } \\
(\mathrm{n}=152)\end{array}$ & $\begin{array}{l}\text { Patients with } \\
\text { chemotherapy } \\
\text { and CT } \\
\text { assessment } \\
(\mathrm{n}=28)\end{array}$ \\
\hline \multicolumn{3}{|l|}{ Gender } \\
\hline Male & 112 & 22 \\
\hline Female & 40 & 6 \\
\hline \multicolumn{3}{|l|}{ Age (years) } \\
\hline Median & 75 & 70 \\
\hline Range & $47-89$ & $47-84$ \\
\hline \multicolumn{3}{|l|}{ Pathological stage } \\
\hline IA & 22 & 1 \\
\hline IB & 12 & 0 \\
\hline IIA & 5 & 0 \\
\hline IIB & 6 & 1 \\
\hline IIIA & 20 & 3 \\
\hline IIIB & 14 & 2 \\
\hline IV & 55 & 21 \\
\hline Unknown & 18 & 0 \\
\hline \multicolumn{3}{|l|}{ Histotype } \\
\hline Adenocarcinoma & 87 & 18 \\
\hline Squamous cell carcinoma & 41 & 6 \\
\hline Adenosquamous cell carcinoma & 1 & 1 \\
\hline Large cell carcinoma & 2 & 0 \\
\hline Pleomorphic carcinoma & 2 & 0 \\
\hline Not otherwise specified & 19 & 3 \\
\hline \multicolumn{3}{|l|}{ EGFR mutation } \\
\hline Positive & 12 & 4 \\
\hline Negative & 44 & 17 \\
\hline Unknown & 96 & 7 \\
\hline
\end{tabular}

using Wilcoxon's rank-sum test. The usefulness of the ERCC1 assessment for predicting chemotherapeutic efficacy was determined using receiver operating characteristic (ROC) curve analysis. ERCC1 expression was compared between the patients whose tumors showed partial response (PR), stable disease (SD), or progressive disease (PD) using the Mann-Whitney $U$-test and Kruskal-Wallis test. $p$-Values $<0.05$ were considered statistically significant.

\section{Results}

Patient characteristics. A total of 169 patients were identified with NSCLC and 152 tumor samples were available for IHC for ERCC1. Twenty-eight patients received platinumcontaining chemotherapy and underwent CT 6-9 weeks after the initiation of chemotherapy. Patient characteristics are shown in Table I. For all patients vs. patients with chemotherapy and CT assessment, respectively, histological types included 87 and 18 adenocarcinomas, 41 and 6 squamous cell carcinomas, 1 and 1 adenosquamous carcinoma, 2 and 0 large cell carcinoma, 2 and 0 pleomorphic carcinoma, and 19 and 3 NSCLC not otherwise specified; TNM staging at the time of sample biopsy indicated 22 and 1 cases were stage Ia, 12 and 0 were stage Ib, 

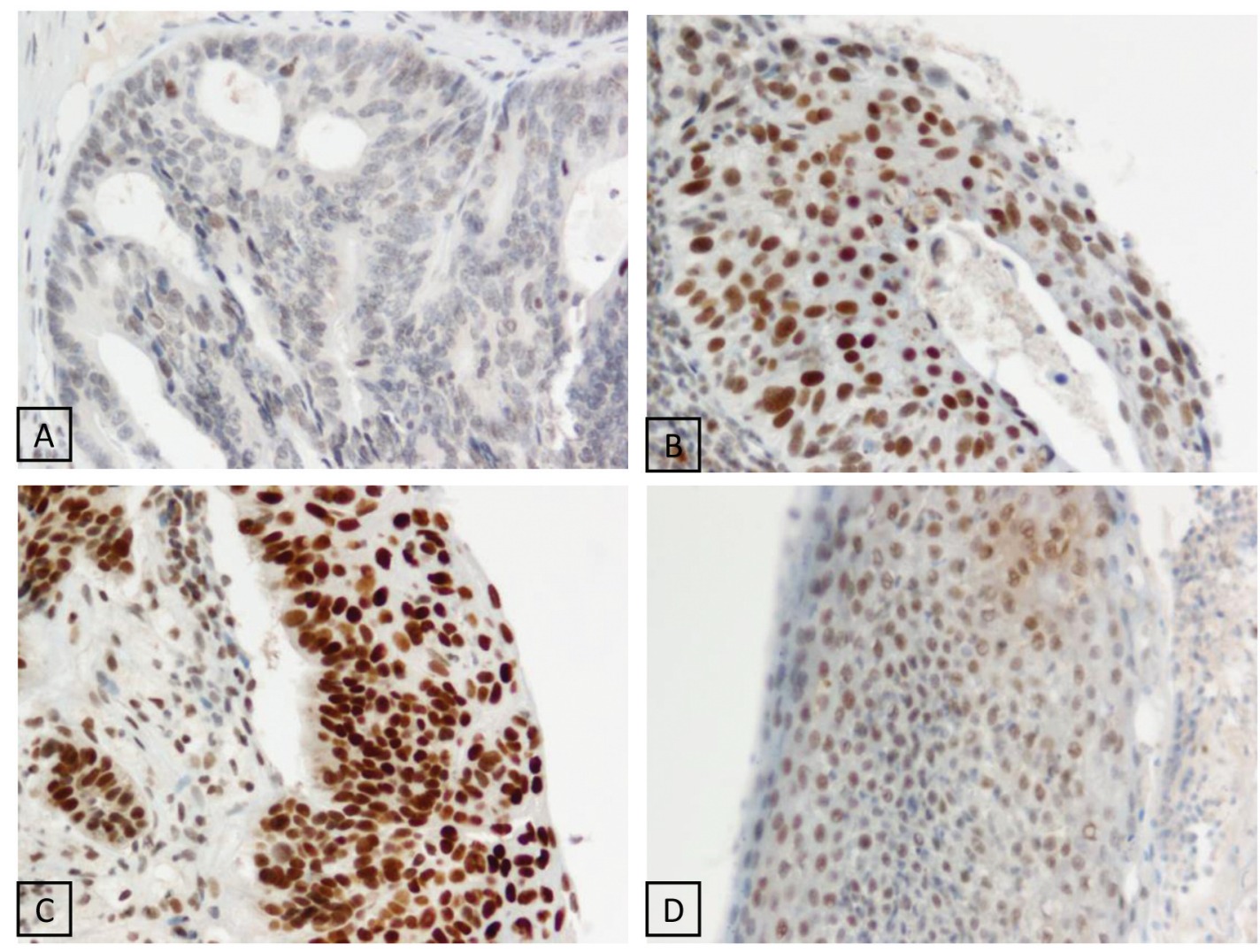

Figure 1. Representative images of tissue sections immunohistochemically stained for ERCC1. A) weak expression, B) moderate expression, C) strong expression, D) positive control (tonsil).

5 and 0 were stage IIa, 6 and 0 were stage IIb, 20 and 1 were stage IIIa, 14 and 2 were stage IIIb, 55 and 21 were stage IV, and 18 and 0 with no staging information; 95 and 18 patients had a smoking history, and 12 and 4 patients had EGFR mutations.

ERCC1 expression in 2012. Representative samples of ERCC1 IHC results are shown in Figure 1. The median H-score for samples stained in 2012 was 2.18 (interquartile range $=1.67$ 3.00). The median $\mathrm{H}$-scores, according to the response to platinum-containing chemotherapy, were 3.00, 2.17, and 2.50 for the patients who showed PD, SD, and PR, respectively $(p=0.059)$ (Figure 2A). The median $\mathrm{H}$-scores between the patients who showed PD and those who showed SD or PR were 3.00 and 2.33 , respectively $(p=0.019)$ (Figure 2B). The median $\mathrm{H}$-score for PD patients was significantly higher than those for SD and PR.

To determine the appropriate cutoff value for predicting efficacy for platinum-containing chemotherapy, an ROC curve was created using the data of 28 patients who received platinum-containing chemotherapy and underwent CT assessment (Figure 2C). Chemotherapy regimens and their responses are shown in Tables II and III. Using a cutoff value of 3.0, ERCC1 could distinguish between SD+PR and PD with a specificity of 0.850 and a sensitivity of 0.750 . The area under the curve was 0.784 [95\% confidence interval $(\mathrm{CI})=0.576-0.993]$. The disease control ratios were $33 \%$ and $90 \%$ in the ERCC1-positive and negative groups, respectively ( $p=0.004$, Fisher's exact test) (Table IV).

ERCC1 expression in 2018. Tissue samples from the tumor biopsies were cut, and the slides were stained with the latest 2018 anti-ERCC1 antibody. The median $\mathrm{H}$-score was 1.50 (interquartile range $=1.00-3.00$ ). The median $\mathrm{H}$-scores according to the response to platinum-containing chemotherapy of the patients who showed PD, SD, and PR were 1.75, 1.03, and 1.50 , respectively $(p=0.262$ ) (Figure $3 \mathrm{~A})$. The median H-scores of the patients who showed PD and those who showed SD or PR were 1.75 and 1.20 , respectively ( $p=0.112$ ) (Figure 3B). The median $\mathrm{H}$-score for patients with PD was likely to be higher than that for SD or PR.

A ROC curve was calculated to assess the usefulness of ERCC1 expression as a biomarker (Figure 3C). Using a cutoff value of 1.33, ERCC1 could distinguish between 
A

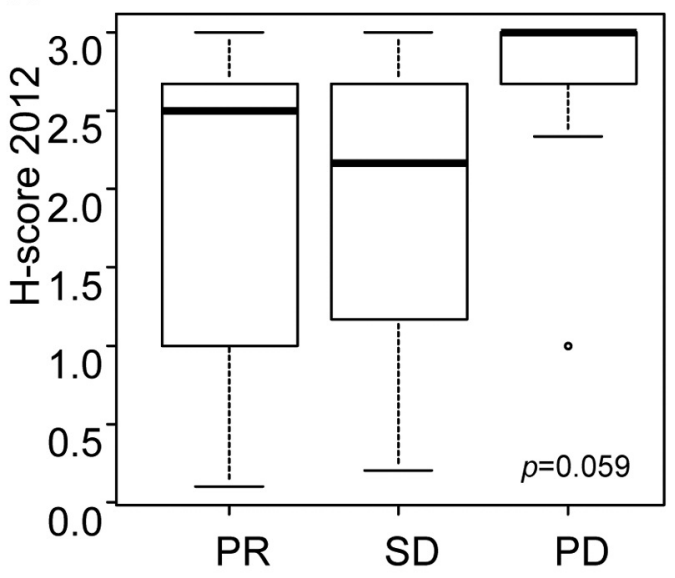

B

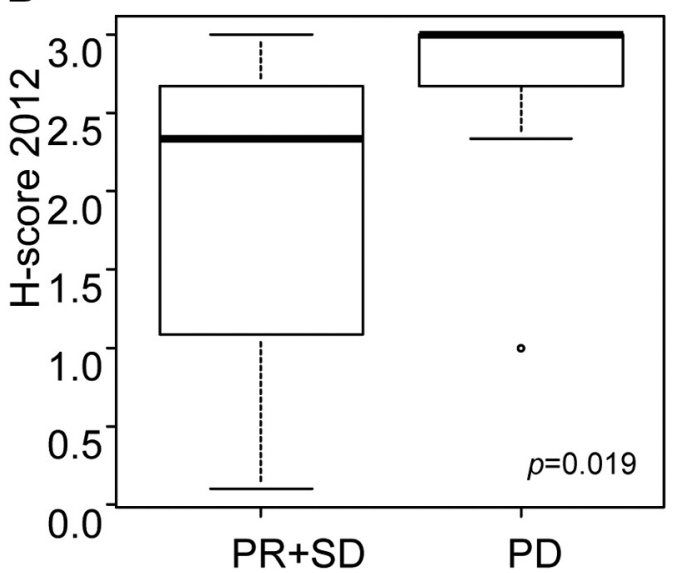

C

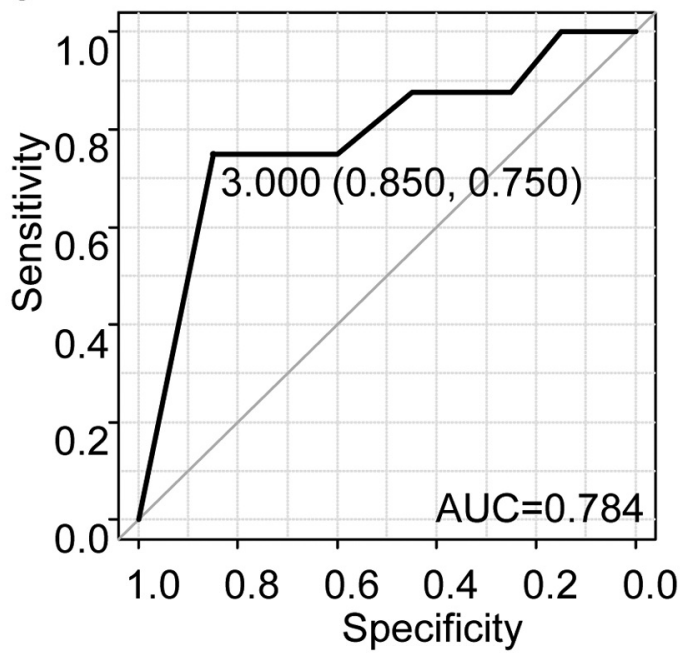

Figure 2. H-score and response to platinum-containing chemotherapy in 2012. (A) The median H-scores of the patients who showed PD, SD, and PR. (B) The median $H$-score for PD patients is significantly higher than that for $S D$ or PR. (C) Using a cut-off value of 3.0, ERCC1 staining distinguishes between $S D+P R$ and $P D$ with a specificity of 0.850 and a sensitivity of 0.750 . The area under the curve is 0.784.PR: Partial response; SD: stable disease; PD: progressive disease.

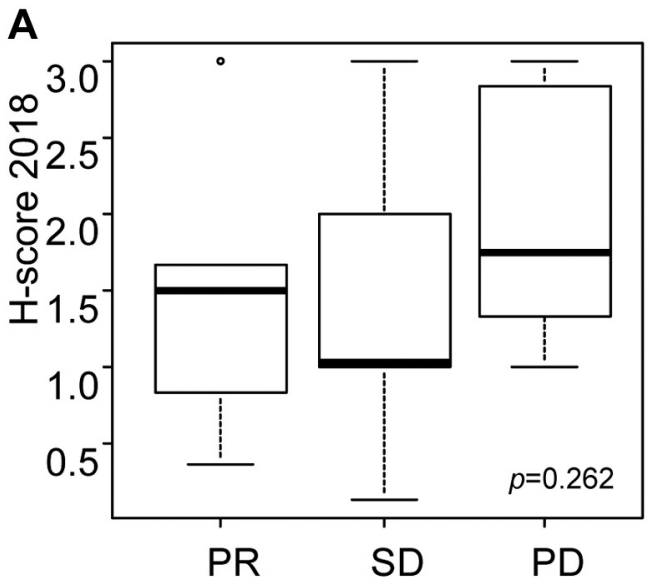

B

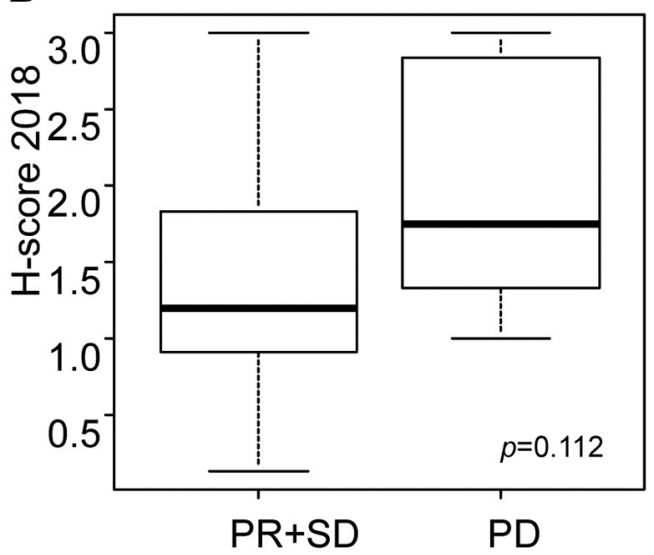

C

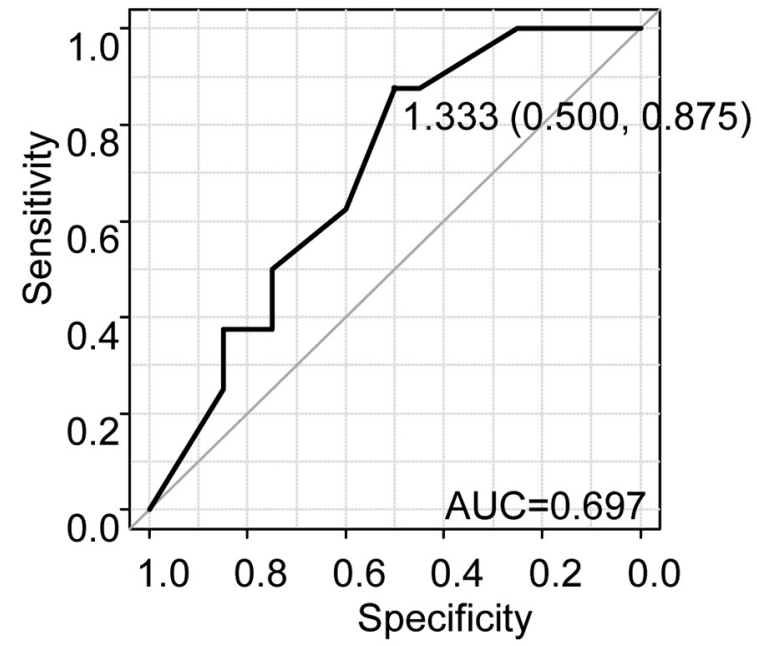

Figure 3. H-score and response to platinum-containing chemotherapy in 2018. (A) The median H-scores of the patients who showed PD, SD, and $P R$ are $1.75,1.03$, and 1.50 , respectively $(p=0.262)$. (B) The median $H$-score for $P D$ patients is likely to be higher than that for $S D$ or PR, 1.75 vs. 1.20, $p=0.112$. (C) Using the cut-off value of 1.33, ERCC1 distinguishes between $S D+P R$ and $P D$ with a specificity of 0.500 and a sensitivity of 0.875. The area under the curve is 0.697. PR: Partial response; SD: stable disease; PD: progressive disease. 
Table II. Number of patients who received platinum-containing chemotherapy in 2012.

\begin{tabular}{lcc}
\hline & ERCC1 positive & ERCC1 negative \\
\hline CBDCA+PTX & 5 & 11 \\
CBDCA+PEM & 1 & 4 \\
CDDP+PEM & 1 & 2 \\
CBDCA+GEM & 0 & 2 \\
CBDCA+VNR & 1 & 0 \\
CDDP+VP-16 & 1 & 0 \\
\hline
\end{tabular}

CBDCA: Carboplatin; CDDP: cisplatin; PTX: paclitaxel; PEM: pemetrexed; GEM: gemcitabine; VNR: vinorelbine; VP-16: etoposide; ERCC1: Excision repair cross-complementing gene 1.

Table III. Number of patients who received platinum-containing chemotherapy in 2018.

\begin{tabular}{lcc}
\hline & ERCC1 positive & ERCC1 negative \\
\hline CBDCA+PTX & 7 & 9 \\
CBDCA+PEM & 3 & 2 \\
CDDP+PEM & 2 & 1 \\
CBDCA+GEM & 0 & 2 \\
CBDCA+VNR & 1 & 0 \\
CDDP+VP-16 & 1 & 0 \\
\hline
\end{tabular}

CBDCA: Carboplatin; CDDP: cisplatin; PTX: paclitaxel; PEM: pemetrexed; GEM: gemcitabine; VNR: vinorelbine; VP-16: etoposide; ERCC1: Excision repair cross-complementing gene 1.

SD+PR and PD with a specificity of 0.500 and a sensitivity of 0.875 . The area under the curve value was 0.697 (95\% CI $=0.497-0.897)$. The disease control ratios were $41.1 \%$ and $90.9 \%$ in the ERCC1-positive and negative groups, respectively ( $p=0.099$, Fisher's exact test) (Table V).

Comparison of H-scores between 2012 and 2018. There was no significant difference between 2012 and 2018 ROC curves $(p=0.436)$ (Figure 4A). Although the correlation coefficient between the H-scores of 2012 and 2018 was $0.538(95 \% \mathrm{CI}=0.206-0.759, p=0.00417)$ (Figure 4B), there were some cases with inconsistencies between 2012 and 2018 (Figure 4C). The H-score of the 2018 IHC results was significantly different from that of 2012 ( $p=0.002$, Wilcoxon's rank-sum test) (Figure 4D).

\section{Discussion}

This study found two important observations. First, patients with tumors that had low ERCC1 expression showed a better disease control rate from platinum-containing chemotherapy. Second, the anti-ERCC1 antibodies from 2012 and 2018 showed differential staining.
Table IV. Response to chemotherapy according to ERCC1 expression in 2012 .

\begin{tabular}{lcc}
\hline & \multicolumn{2}{c}{ Partial response and stable disease } \\
\cline { 2 - 3 } & + & - \\
\hline ERCC1 positive $(\mathrm{H}$-score=3) & 3 & 6 \\
ERCC1 negative $(\mathrm{H}-\mathrm{score}<3)$ & 18 & 2 \\
\hline
\end{tabular}

$p=0.004$ (Fisher's exact test). ERCC1: Excision repair crosscomplementing gene 1 .

Table V. Response to chemotherapy according to ERCC1 expression in 2018 .

\begin{tabular}{lcc}
\hline & \multicolumn{2}{c}{ Partial response and stable disease } \\
\cline { 2 - 3 } & + & - \\
\hline ERCC1 positive $(\mathrm{H}$-score $\geq 2)$ & 8 & 6 \\
ERCC1 negative $(\mathrm{H}-\mathrm{score}<2)$ & 13 & 2 \\
\hline
\end{tabular}

$p=0.109$ (Fisher's exact test). ERCC1: Excision repair crosscomplementing gene 1 .

Not only did patients with tumors that had low ERCC1 expression show a significantly better disease control rate from platinum-containing chemotherapy when assessed using the anti-ERCC1 antibody from 2012, the anti-ERCC1 antibody from 2018 also showed that patients with low ERCC1 expression were likely to benefit from platinum-containing chemotherapy compared to those with high ERCC1 expression. Consistent with previous reports, these data suggest that ERCC1 can be a predictive marker of platinum-containing chemotherapy. Since a negative result was reported in 2017 (9), some reports have shown the usefulness of ERCC1 as a predictive marker $(14,15)$. Piljic et al. retrospectively assessed ERCC1 expression using IHC and reported that longer overall survival was strongly associated with low ERCC1 expression in patients who received platinum-containing chemotherapy compared with patients with high ERCC1 expression. While they used the 4F9 clone of the anti-ERCC1 antibody (DACO, Glostrup, Denmark), this study used the 8F1 clone, which was the most frequently used in previous studies (16). These results suggest that both of the commercially available anti-ERCC1 antibodies can be used to predict the efficacy of platinumcontaining chemotherapy. Although a prospective ERCC1 trial in which chemotherapeutic drugs were chosen based on 
A

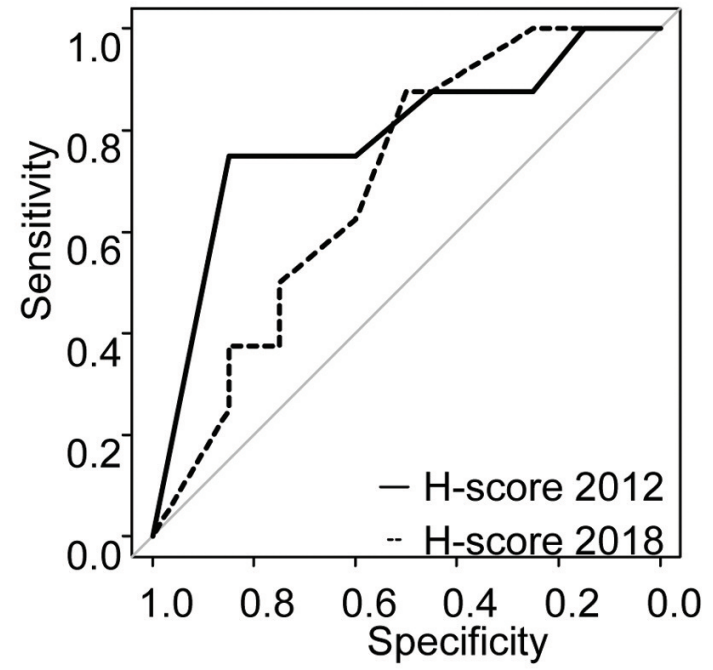

C

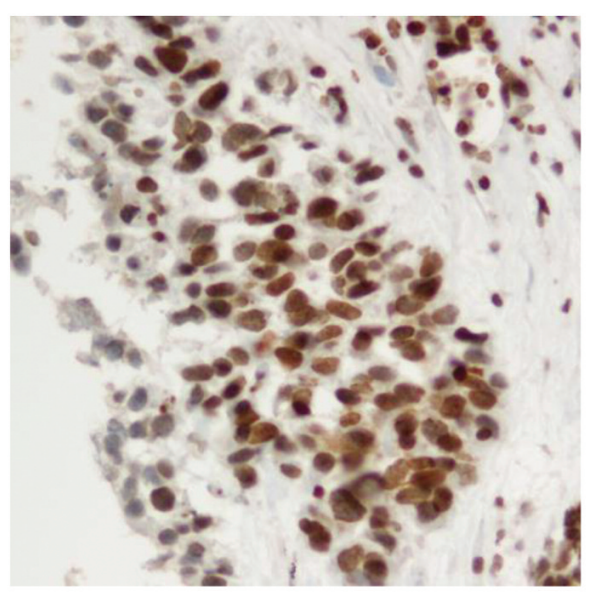

2012
B
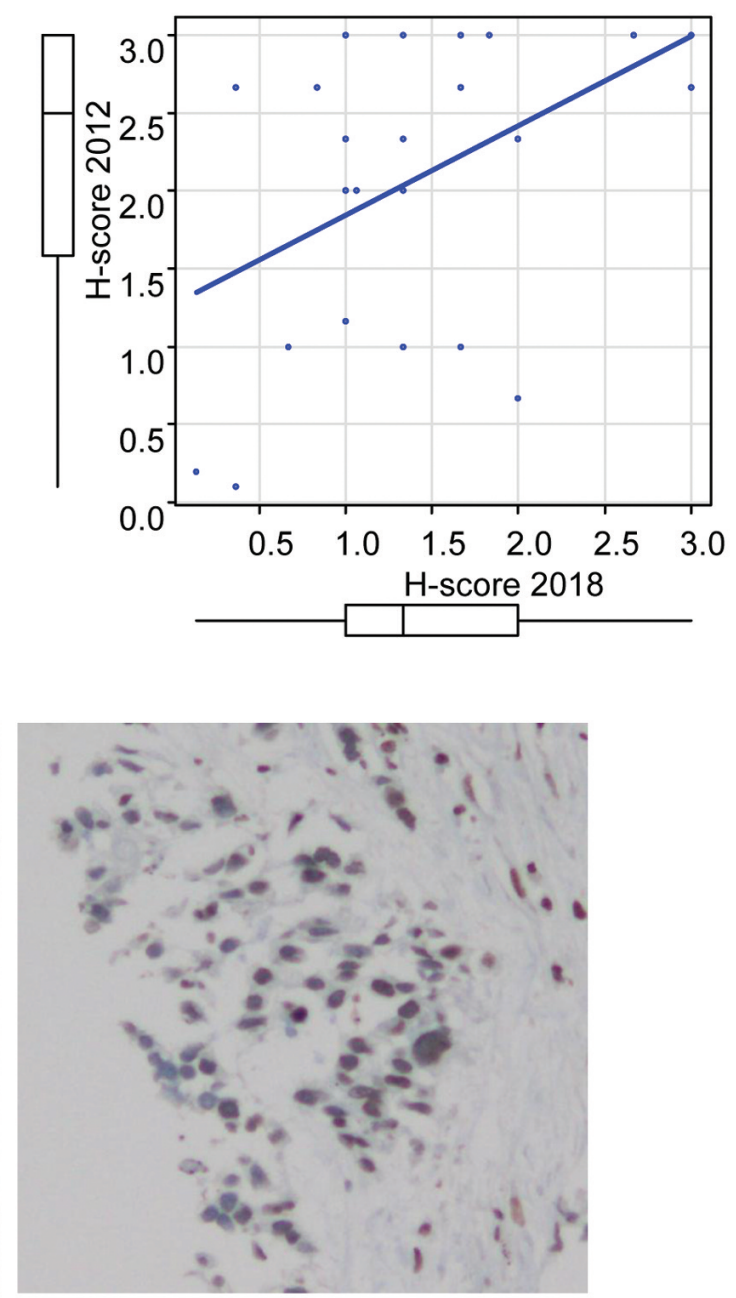

2018

D

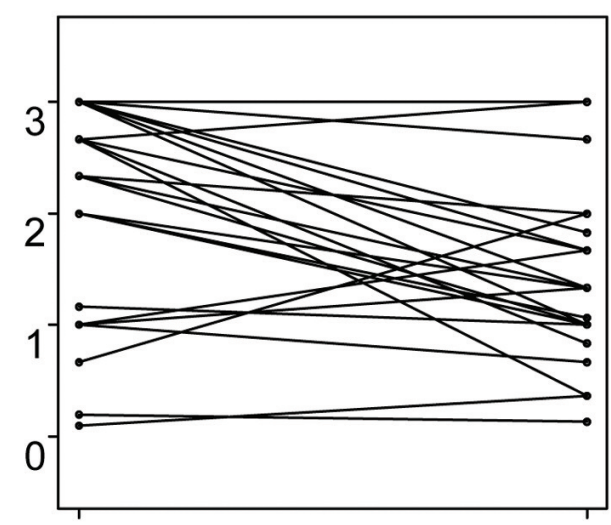

H-score 2012

H-score 2018

Figure 4. Comparison of H-scores between 2012 and 2018. (A) There is no significant difference in the area under the curve (AUC) between 2012 and 2018 ( $p=0.436)$. (B) The correlation coefficient between the H-score of 2012 and 2018 was 0.538 (95\%CI=0.206-0.759, $p=0.00417)$. (C) The sample was strongly stained in 2012 but weakly stained in 2018, demonstrating inconsistent results in H-scores between 2012 and 2018. (D) The $H$-scores of 2012 and 2018 are significantly different ( $p=0.002$, Wilcoxon's rank-sum test). 
ERCC1 expression did not show a prolonged survival due to the antibody batch issue, ERCC 1 itself can be a promising predictive biomarker.

Second, the anti-ERCC1 antibodies in 2012 and 2018 showed different IHC results. In this study, the same tumor samples were stained twice, six years apart. Although both $\mathrm{H}$-scores were correlated with each other, there was a significant difference between the IHC results of the corresponding samples. This result is consistent with a previous study that reported discrepancies between $8 \mathrm{~F} 1$ antibody batches tested in 2006 and 2011 (17). These results suggest that the performance of the $8 \mathrm{~F} 1$ antibody changed between 2006 and 2011 and changed again between 2012 and 2018. Therefore, it is very difficult to determine the appropriate cutoff value to predict the response to chemotherapy using the 8F1 antibody.

Several methods have been used to assess ERCC1 expression. These include IHC, quantitative PCR, and single nucleotide polymorphisms. In our study, IHC with the 8F1 antibody was adopted, which was not suitable for long-term use. Previous studies have shown that the ERCC1-202 isoform is the only functional isoform out of the four isoforms. Although its importance was emphasized, there were no ERCC1-202 specific antibodies $(17,18)$. Kuo et al. established a novel antibody that specifically detects ERCC1-202. This technology may be a breakthrough in ERCC1 assessment (19). Using quantitative PCR, Wang et al. reported that high expression of ERCC1-202 was an independent predictive factor for progression-free survival in platinum-based chemotherapy (20). Moreover, RNA sequencing technology has improved, which will enable the assessment of not only ERCC1 isoform mRNA expression but also related gene expression. Now is the time to evaluate ERCC1 as a biomarker using these new technologies.

This study had several limitations. First, the number of patients evaluated in this study was small. However, even with this small number, statistically significant differences in chemotherapy response between patients with ERCC1positive and negative tumors were found, which in turn indicates that ERCC1 is a powerful tool to predict the response. Second, there is a possibility that the change in the IHC results between the 2012 and 2018 tests is associated with tissue degradation over time rather than antibody performance. The old antibody was not available; therefore, the samples could not be tested at the same time using the old and latest antibodies. However, since the tumor samples were kept in a room dedicated to sample storage in our hospital, the amount of degradation should be minimized.

\section{Conclusion}

Since platinum-based chemotherapy is a key treatment for NSCLC, it is important to predict the efficacy of the therapy in order to individualize it for patients. Patients with tumors having low ERCC1 expression showed a better disease control rate from platinum-containing chemotherapy. However, the performance of the antibody used for IHC changed over time, suggesting that new technology to standardize the evaluation of ERCC1 expression is necessary.

\section{Conflicts of Interest}

The Authors declare no conflicts of interest in relation to this study.

\section{Authors' Contributions}

TO, YT, and TI: conception and study design; TO, RT, MN, TH, $\mathrm{MH}$, and SH: collection of data; TO, YT, AA, and TI: analysis and interpretation of data; TO, YT, RT, MN, TH, MH, AA, and MC: drafting and revision of the article. All Authors approved the final version of the article.

\section{Acknowledgements}

The Authors would like to thank Editage (www.editage.jp) for English language editing.

\section{Funding}

This study was supported by the Japan Society for the Promotion of Science KAKENHI (Grant Number: 16K19313) (Tokyo, Japan).

\section{References}

1 Scagliotti GV, Parikh P, von Pawel J, Biesma B, Vansteenkiste J, Manegold C, Serwatowski P, Gatzemeier U, Digumarti R, Zukin M, Lee JS, Mellemgaard A, Park K, Patil S, Rolski J, Goksel T, de Marinis F, Simms L, Sugarman KP and Gandara D: Phase III study comparing cisplatin plus gemcitabine with cisplatin plus pemetrexed in chemotherapy-naive patients with advanced-stage non-small-cell lung cancer. J Clin Oncol 26(21): 3543-3551, 2008. PMID: 18506025. DOI: 10.1200/JCO.2007.15.0375

2 Reed E: ERCC1 and clinical resistance to platinum-based therapy. Clin Cancer Res 11(17): 6100-6102, 2005. PMID: 16144907. DOI: 10.1158/1078-0432.CCR-05-1083

3 Yu JJ, Lee KB, Mu C, Li Q, Abernathy TV, Bostick-Bruton F and Reed E: Comparison of two human ovarian carcinoma cell lines (A2780/CP70 and MCAS) that are equally resistant to platinum, but differ at codon 118 of the ERCC1 gene. Int J Oncol 16(3): 555-560, 2000. PMID: 10675489. DOI: 10.3892/ijo.16.3.555

4 Yu JJ, Mu C, Lee KB, Okamoto A, Reed EL, Bostick-Bruton F, Mitchell KC and Reed E: A nucleotide polymorphism in ERCC1 in human ovarian cancer cell lines and tumor tissues. Mutat Res 382(1-2): 13-20, 1997. PMID: 9360634. DOI: 10.1016/s13835726(97)00004-6

5 Viguier J, Boige V, Miquel C, Pocard M, Giraudeau B, Sabourin JC, Ducreux M, Sarasin A and Praz F: ERCC1 codon 118 polymorphism is a predictive factor for the tumor response to oxaliplatin/5-fluorouracil combination chemotherapy in patients with advanced colorectal cancer. Clin Cancer Res 11(17): 62126217, 2005. PMID: 16144923. DOI: 10.1158/1078-0432.CCR04-2216 
6 Holm B, Mellemgaard A, Skov T and Skov BG: Different impact of excision repair cross-complementation group 1 on survival in male and female patients with inoperable non-smallcell lung cancer treated with carboplatin and gemcitabine. J Clin Oncol 27(26): 4254-4259, 2009. PMID: 19667277. DOI: 10.1200/JCO.2008.18.8631

7 Arriagada R, Bergman B, Dunant A, Le Chevalier T, Pignon JP, Vansteenkiste $\mathrm{J}$ and International Adjuvant Lung Cancer Trial Collaborative Group: Cisplatin-based adjuvant chemotherapy in patients with completely resected non-small-cell lung cancer. N Engl J Med 350(4): 351-360, 2004. PMID: 14736927. DOI: 10.1056/NEJMoa031644

8 Olaussen KA, Dunant A, Fouret P, Brambilla E, André F, Haddad V, Taranchon E, Filipits M, Pirker R, Popper HH, Stahel R, Sabatier L, Pignon JP, Tursz T, Le Chevalier T, Soria JC and IALT Bio Investigators: DNA repair by ERCC1 in non-smallcell lung cancer and cisplatin-based adjuvant chemotherapy. $\mathrm{N}$ Engl J Med 355(10): 983-991, 2006. PMID: 16957145. DOI: 10.1056/NEJMoa060570.

9 Lee SM, Falzon M, Blackhall F, Spicer J, Nicolson M, Chaudhuri A, Middleton G, Ahmed S, Hicks J, Crosse B, Napier M, Singer JM, Ferry D, Lewanski C, Forster M, Rolls SA, Capitanio A, Rudd R, Iles N, Ngai Y, Gandy M, Lillywhite R and Hackshaw A: Randomized prospective biomarker trial of ERCC1 for comparing platinum and nonplatinum therapy in advanced non-small-cell lung cancer: ERCC1 Trial (ET). J Clin Oncol 35(4): 402-411, 2017. PMID: 27893326. DOI: 10.1200/ JCO.2016.68.1841

10 Righi L, Papotti MG, Ceppi P, Billè A, Bacillo E, Molinaro L, Ruffini E, Scagliotti GV and Selvaggi G: Thymidylate synthase but not excision repair cross-complementation group 1 tumor expression predicts outcome in patients with malignant pleural mesothelioma treated with pemetrexed-based chemotherapy. J Clin Oncol 28(9): 1534-1539, 2010. PMID: 20177021. DOI: 10.1200/JCO.2009.25.9275

11 Vilmar AC, Santoni-Rugiu E and Sørensen JB: ERCC1 and histopathology in advanced NSCLC patients randomized in a large multicenter phase III trial. Ann Oncol 21(9): 1817-1824, 2010. PMID: 20332140. DOI: 10.1093/annonc/mdq053

12 Okimoto T, Tsubata Y, Sutani A, Fuchita H, Koba N, Hotta T, Hamaguchi M, Miura K, Hamaguchi S, Ohe M, Kuraki T, Harada Y, Maruyama R, Miyamoto N, Kishimoto K and Isobe $\mathrm{T}$ : Immunohistochemical comparison of biomarker expression in biopsy and surgical specimens of non-small cell lung cancer. Anticancer Res 34(6): 2755-2761, 2014. PMID: 24922636.

13 Kanda Y: Investigation of the freely available easy-to-use software 'EZR' for medical statistics. Bone Marrow Transplant 48(3): 452-458, 2013. PMID: 23208313. DOI: 10.1038/ bmt.2012.244
14 Villalobos M, Czapiewski P, Reinmuth N, Fischer JR, Andreas S, Kortsik C, Serke M, Wolf M, Neuser P, Reuss A, Schnabel PA and Thomas M: ERCC1 assessment in upfront treatment with and without cisplatin-based chemotherapy in stage IIIB/IV nonsquamous non-small cell lung cancer. Med Oncol 35(7): 106, 2018. PMID: 29905882. DOI: 10.1007/s12032-018-1169-5

15 Piljić Burazer M, Mladinov S, Matana A, Kuret S, Bezić J and Glavina Durdov M: Low ERCC1 expression is a good predictive marker in lung adenocarcinoma patients receiving chemotherapy based on platinum in all TNM stages - a single-center study. Diagn Pathol 14(1): 105, 2019. PMID: 31521181. DOI: 10.1186/s13000-019-0885-2

16 Bahamon BN, Gao F and Danaee H: Development and validation of an ERCC1 immunohistochemistry assay for solid tumors. Arch Pathol Lab Med 140(12): 1397-1403, 2016. PMID: 27610644. DOI: 10.5858/arpa.2016-0006-OA

17 Friboulet L, Olaussen KA, Pignon JP, Shepherd FA, Tsao MS, Graziano S, Kratzke R, Douillard JY, Seymour L, Pirker R, Filipits M, André F, Solary E, Ponsonnailles F, Robin A, Stoclin A, Dorvault N, Commo F, Adam J, Vanhecke E, Saulnier P, Thomale J, Le Chevalier T, Dunant A, Rousseau V, Le Teuff G, Brambilla E and Soria JC: ERCC1 isoform expression and DNA repair in non-small-cell lung cancer. N Engl J Med 368(12): 1101-1110, 2013. PMID: 23514287. DOI: 10.1056/NEJMoa 1214271

18 Friboulet L, Postel-Vinay S, Sourisseau T, Adam J, Stoclin A, Ponsonnailles F, Dorvault N, Commo F, Saulnier P, SalomeDesmoulez S, Pottier G, André F, Kroemer G, Soria JC and Olaussen KA: ERCC1 function in nuclear excision and interstrand crosslink repair pathways is mediated exclusively by the ERCC1-202 isoform. Cell Cycle 12(20): 3298-3306, 2013. PMID: 24036546. DOI: 10.4161/cc.26309

19 Kuo MS, Adam J, Dorvault N, Robin A, Friboulet L, Soria JC and Olaussen KA: A novel antibody-based approach to detect the functional ERCC1-202 isoform. DNA Repair (Amst) 64: 3444, 2018. PMID: 29482102. DOI: 10.1016/j.dnarep.2018.02.002

20 Wang X, Zhu X, Zhang H, Fan X, Xue X, Chen Y, Ding C, Zhao $\mathrm{J}$ and Wu G: ERCC1_202 is a prognostic biomarker in advanced stage non-small cell lung cancer patients treated with platinumbased chemotherapy. J Cancer 8(14): 2846-2853, 2017. PMID: 28928874. DOI: $10.7150 /$ jca. 19897
Received March 3, 2021

Revised March 17, 2021

Accepted March 19, 2021 